\title{
Scale Interactions in Turbulence for Mountain Blowing Snow ${ }^{\mathscr{O}}$
}

\author{
N. O. AKsamit And J. W. Pomeroy \\ Centre for Hydrology, University of Saskatchewan, Saskatoon, Saskatchewan, Canada
}

(Manuscript received 18 September 2017, in final form 28 November 2017)

\begin{abstract}
Blowing snow particle transport responds to wind motions across many length and time scales. This coupling is nonlinear by nature and complicated in atmospheric flows where eddies of many sizes are superimposed. In mountainous terrain, wind flow descriptions are further complicated by topographically influenced or enhanced flows. To improve the current understanding and modeling of blowing snow transport in complex terrain, statistically significant timing and frequencies of wind-snow coupling were identified in high-frequency observations of surface blowing snow and near-surface turbulence from a mountain field site in the Canadian Rockies. Investigation of the mechanisms influencing near-surface, high-frequency turbulence and snow concentration fluctuations provided strong evidence for amplitude modulation from large-scale motions. The large-scale atmospheric motions modulating near-surface turbulence and snow transport were then compared to specific quadrant analysis structures recently identified as relevant for outdoor blowing snow transport. The results suggest that large atmospheric structures modulate the amplitude of high-frequency turbulence and modify turbulence statistics typically used to model blowing snow. Additionally, blowing snow was preferentially redistributed under the footprint of these same sweep motions, with both low- and high-frequency coherence increasing in their presence.
\end{abstract}

\section{Introduction}

Redistribution of snow by wind is an environmental two-phase flow with great spatiotemporal variability. Blowing snow has implications for cold-region hydrology and engineering, avalanche safety, and glaciology, as well as Antarctic and Greenland surface mass balance (Dyunin and Kotlyakov 1980; Pomeroy et al. 1993; Freitag and McFadden 1997; Schweizer et al. 2003; Scarchilli et al. 2010, Lenaerts et al. 2012). Redistribution of snow begins when wind drag and shear stress exceed transport thresholds, and snow grains mobilize on the surface ( $\mathrm{Li}$ and Pomeroy 1997). Subsecond shear stress peaks can be sufficient to initiate snow transport and may not be reflected in timeaveraged mean values (Aksamit and Pomeroy 2016). Once in motion, blowing snow is characterized by a variety of length and time scales, from centimeter hop-lengths and rebound times for grains in saltation

Supplemental information related to this paper is available at the Journals Online website: https://doi.org/10.1175/JHM-D-170179.s1.

Corresponding author: Nikolas Aksamit,n.aksamit@usask.ca at the surface (Nemoto et al. 2004) to turbulent eddy length scales and bursting frequencies for particles in suspension that closely follow wind streamlines (Bintanja 1998, 2000). The choice of representative time scale has considerable effect on the performance of all aeolian transport models in the presence of multiple scales of atmospheric motions (Bisantino et al. 2010). Much is still unknown about the coupling of turbulent wind motions and snow transport in natural terrain, though the importance of turbulent bursts is widely accepted.

Instantaneous wind speed fluctuations and atmospheric structures are vital components for understanding intermittent aeolian behavior (Sterk et al. 1998; Leenders et al. 2005; Wiggs and Weaver 2012). To better represent the role of turbulent motions in snow transport models, researchers are gradually moving away from traditional approaches of modeling blowing snow as a steady-state process driven by time-averaged data (e.g., Nemoto and Nishimura 2004; Groot Zwaaftink et al. 2014), yet models continue to rely on experimentally derived relationships between wind and snow response, largely from low Reynolds number wind tunnel experiments (e.g., Nishimura and Hunt 2000; Clifton et al. 2006). 
Modeling wind-snow coupling in truly complex turbulence, such as found in alpine environments, also requires understanding the physical mechanisms generating turbulence at very high Reynolds numbers. Recent research in very high Reynolds number wind tunnels, large-eddy simulations, and some limited results with atmospheric flows have linked the modulation of high-frequency surface turbulence to the passage of large-scale coherent motions (Hutchins and Marusic 2007a; Mathis et al. 2009a, b, 2011, 2013; Anderson 2016; Jacob and Anderson 2017). This has provided new insight into the cascade of turbulent energy and the dissipation of momentum in large coherent structures. It has been shown that the superposition of large-scale motions on local surface turbulence does not behave as a simple shift of mean velocity (Hutchins and Marusic 2007b); rather, the modification of high-frequency turbulence by large-scale motions directly affects turbulence statistics and surface shear stress in high Reynolds number flows. This has not yet been investigated in mountainous terrain, but would imply fundamental differences in the mechanics driving blowing snow in wind tunnel and atmospheric studies and the calculations used to characterize the physical process. This suggests that considerable caution and discretion must be exercised in extrapolating wind tunnel observations to outdoor blowing snow transport phenomena.

Most analysis connecting turbulent motions and saltation has been conducted in the time domain (Liu et al. 2012) and has associated limitations. The temporal lag between the two signals caused by particle inertia and the superposition of a wide variety of scales of atmospheric motions result in better analysis with spectral methods (e.g., Venditti and Bennett 2000; Schönfeldt and von Löwis 2003; Baas 2006; Ellis 2006; Liu et al. 2009, 2012). Quantitative coupling of turbulent structures with sediment response in given frequency ranges is difficult in natural conditions, but some promising progress has been made in wind tunnels (e.g., Liu et al. 2012; Paterna 2016, 2017).

However, rescaling these kind of steady-state wind tunnel relationships to environmental flows is often complicated because the mechanics of transport are a function of turbulence structure, which is in turn influenced by surface topography and mesoscale winds (e.g., Wiggs and Weaver 2012; Chapman et al. 2013). Even mass flux rates and threshold friction velocities vary with turbulence intensity, which is often found to be substantially greater in complex terrain than wind tunnels or horizontally homogenous and flat terrain (Xuan 2004). Exactly how turbulence characteristics in the atmosphere determine the variability and time-averaged properties of saltation remains a critical challenge in aeolian research (Kok et al. 2012). It is still an open question whether top-down or bottom-up motions are more appropriate conceptualizations of the coherent structures driving sediment transport (Bauer et al. 1998; Sterk et al. 1998; Baas 2008).

The objective of this study is to investigate the coherence between intermittent snow transport and turbulent gusts as a coupled nonlinear system to better inform semideterministic models of transport (Bauer et al. 2013). To investigate this, $50-\mathrm{Hz}$ field measurements of wind and blowing snow density were collected at a study site in the Canadian Rockies. Statistically significant times and frequencies of wind-snow coupling were identified with wavelet coherence testing. Through amplitude modulation, the role of large-scale motions on high-frequency wind eddies and blowing snow transport was investigated. Further analysis of the mechanics of significant large motions using quadrant analysis structures was compared to recent blowing snow-coherent structure insights (Aksamit and Pomeroy 2018).

\section{Methods}

\section{a. Fieldwork}

Blowing snow observations were collected during nighttime field experiments between November 2015 and March 2016, at the Fortress Mountain Snow Laboratory (FMSL; 50 $49^{\prime} 21^{\prime \prime} \mathrm{N}, 115^{\circ} 11^{\prime} 54^{\prime \prime} \mathrm{W}$ ), Kananaskis Valley, Alberta, Canada (Fig. 1). The experimental site was surrounded by relatively flat terrain on a bench above the main valley at $2000 \mathrm{~m}$ MSL. Nearby steep alpine faces rise from valley-bottom elevations of $1500 \mathrm{~m}$ to $2900-\mathrm{m}$ ridge tops over distances of less than $5.5 \mathrm{~km}$. The surrounding terrain was snow covered, and shrub vegetation was buried for the duration of the experiment, with snow depths varying from 40 to $80 \mathrm{~cm}$ depending on daily erosion and deposition. The height of snow varied no more than $5 \mathrm{~cm}$ during any one night of recording. The site was suitable for the observation of the mesoscale influence of topographically driven flows with no immediate $(\leq 200 \mathrm{~m})$ bluff body interference. The same valley was found to have extraordinarily high turbulence intensity and evidence of advection of turbulent bursts from ridgelines to the valley bottom (Helgason and Pomeroy 2012). FMSL can receive $800 \mathrm{~mm}$ of water as snowfall each winter and can sustain winds exceeding $35 \mathrm{~m} \mathrm{~s}^{-1}$. Snow redistribution by wind is substantial at FMSL, with winter snow depths varying from zero on ridgetops to $5 \mathrm{~m}$ in gullies where snowdrifts develop.

Two Campbell Scientific CSAT3 ultrasonic anemometers were positioned on a single mast to measure wind speed at $50 \mathrm{~Hz}$ in three dimensions at two fixed heights above the ground. Measurement heights varied above the snow surface between $0.10-0.40$ and $1.40-1.70 \mathrm{~m}$. 


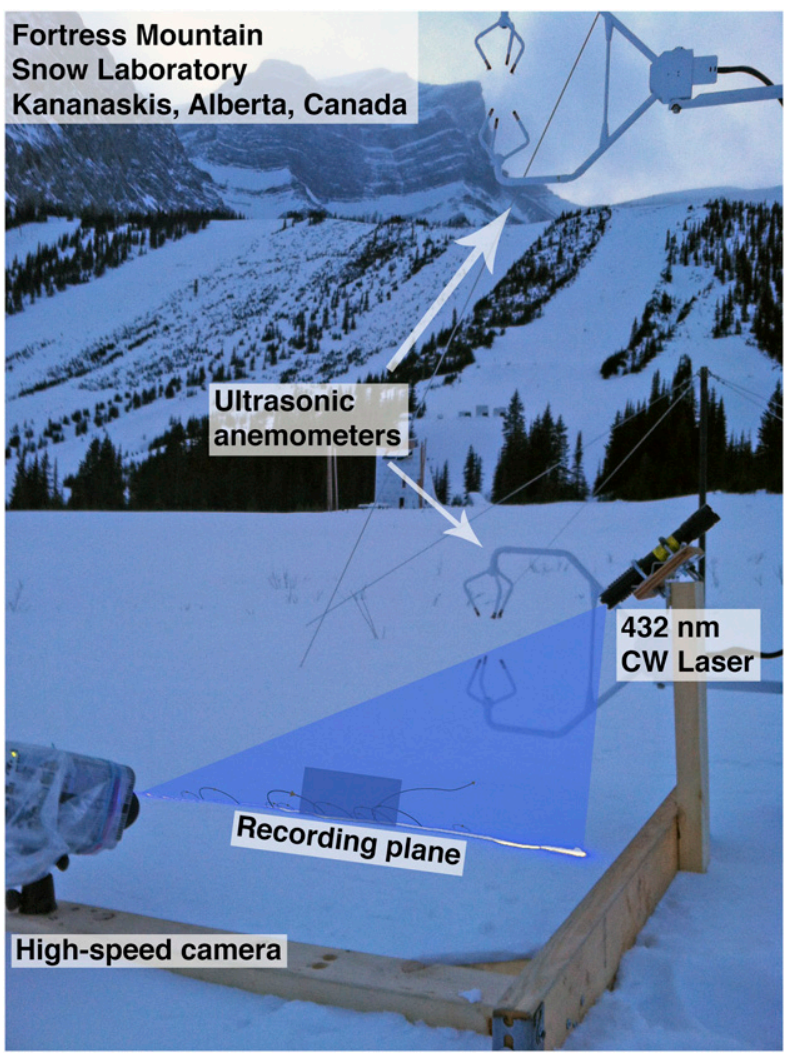

FIG. 1. Blowing snow recording apparatus with nearby wind measurements at FMSL, Kananaskis, Alberta, Canada. The recording plane indicates the location of camera focus inside the illumination plane. The wind is oriented parallel with the plane and toward the continuous wave $(\mathrm{CW})$ laser in this schematic.

The location of the lower sonic anemometer, with a pathlength of $15 \mathrm{~cm}$, can result in a certain amount of high-frequency energy that is not measured. Estimates of the high-frequency losses for each anemometer during each night of recording are provided in the online supplementary materials.

Blowing snow observations were made with the laservideo system described by Aksamit and Pomeroy (2016, 2018). The camera was situated $0.30 \mathrm{~m}$ from the anemometer mast, in a spanwise orientation to the wind (Fig. 1), and was rotated throughout the observation periods to keep the laser illumination plane parallel to the dominant wind direction. The camera then recorded a plane $(\sim 30 \mathrm{~mm} \times 140 \mathrm{~mm})$ of the flow of saltating snow (Fig. 1). To capture the influence of large eddies responsible for the strongest sediment transport fluctuations (Schönfeldt and von Löwis 2003; Baas 2006; Liu et al. 2009), several long, 5-19-min videos of nighttime snow particle transport at 50-100 frames per second were recorded each night. Each blowing snow video recording consisted of $2.7-5.8 \times 10^{4}$ frames, depending on aspect ratio and frame resolution, totaling $4.1 \mathrm{~h}$ for 23 blowing snow recordings over five nights.

Descriptions of the snow surface, snow densities from the top $5 \mathrm{~cm}$ of the snowpack, average air and snow surface temperatures, surface hand hardness indices (HHIs), mobile grain diameters, and 15-min mean wind speed ranges for the five nights are found in Table 1. Wind and video measurements were synchronized at the onset of nightly recording to minimize datalogger drift. Each night exhibited slightly stable stratification, and wind measurements for each recording were subjected to a dual-axis rotation such that $u$ was parallel to the streamwise direction, and the spanwise and vertical winds ( $v$ and $w$, respectively) had a zero mean, following Kaimal and Finnigan (1994).

As amplitude modulation studies have never been conducted during blowing snow storms, it was important to consider the influence of blowing snow particles on the wind as well as the effect of large scale motions. Data from Paterna et al. (2016) were utilized for a low Reynolds number comparison of the role of large turbulent structures modulating surface turbulence and blowing snow. Specifically, 20-Hz directional snow flux and wind speed fluctuations were subjected to the same analysis as the FMSL data.

\section{b. Blowing snow density estimation}

Grayscale blowing snow video recordings were binarized following the algorithm of Otsu (1979), to obtain blowing snow particle concentrations per frame. A binarization threshold was determined for each frame to account for varying illumination depending on density of saltation. Similar techniques have been used in wind tunnel sand transport concentration studies (e.g., Liu et al. 2012) and environmental blowing snow studies (e.g., Gordon et al. 2009; Aksamit and Pomeroy 2016, 2018). After binarization, quality controls were implemented to eliminate false-positive snow measurements from camera sensor "hot spots" during periods of low transport as well as to adjust for low-light conditions during periods of high transport when the laser was largely obscured. A flood-fill algorithm was then implemented to identify individual snow particles and estimate their equivalent particle diameters. Assumptions of particle sphericity and constant snow particle density equal to ice $\left(917 \mathrm{~kg} \mathrm{~m}^{-3}\right)$ allowed estimation of airborne blowing snow density $\rho_{\text {bs }}\left(\mathrm{kg} \mathrm{m}^{-3}\right)$ per frame as by Aksamit and Pomeroy $(2016,2018)$.

\section{c. Signal processing}

\section{1) WAVELET ANALysis}

Wavelet analysis has emerged as the standard technique to detect intermittent behavior in geophysical 
TABLE 1. Snow surface and meteorological conditions during each night of blowing snow. Missing values are indicated by -

\begin{tabular}{|c|c|c|c|c|c|c|}
\hline & $\begin{array}{c}\text { Surface } \\
\text { description }\end{array}$ & $\begin{array}{c}\text { Snow surface } \\
\text { density }\left(\mathrm{kg} \mathrm{m}^{-3}\right)\end{array}$ & $\begin{array}{c}\text { Air/snow } \\
\text { surface temp }\left({ }^{\circ} \mathrm{C}\right)\end{array}$ & $\begin{array}{c}\text { Surface } \\
\text { hardness }(\mathrm{HHI})\end{array}$ & $\begin{array}{l}\text { Grain size } \\
\text { range }(\mathrm{mm})\end{array}$ & $\begin{array}{l}\text { Mean } 0.4 \mathrm{~m} \text { wind } \\
\text { speeds }\left(\mathrm{m} \mathrm{s}^{-1}\right)\end{array}$ \\
\hline 20 Nov 2015 & $2-3 \mathrm{~cm}$ wind slab & - & $-10 /-$ & Pencil & - & $2.7-3.9$ \\
\hline 4 Dec 2015 & $\begin{array}{l}\text { Pockets of drifted } \\
\text { snow on wind slab }\end{array}$ & 390 & $-3 /-4$ & Pencil & $0.25-0.75$ & $2.4-6.4$ \\
\hline 7 Dec 2015 & $1 \mathrm{~cm}$ fresh on wind slab & 137 & $-3 /-3.5$ & 4 finger & $0.5-1.5$ & $1.5-3.0$ \\
\hline 3 Feb 2016 & $\begin{array}{l}\text { Fine decomposing grains } \\
\text { on wind slab/sastrugi }\end{array}$ & 262 & $-10 /-10$ & 1 finger/pencil & $0.5-1$ & $3.6-5.7$ \\
\hline 3 Mar 2016 & Fresh snow, not snowing & 156 & $-2 /-5$ & Fist & 0.5 & $3.5-4.8$ \\
\hline
\end{tabular}

systems in the time-frequency domain (e.g., FoufoulaGeorgiou and Kumar 1994; Torrence and Compo 1998; Grinsted et al. 2004). In comparison to Fourier methods, wavelets are (imperfectly) localized in time and frequency, and wavelet convolution requires only local stationarity under the image of the wavelet. This results in better identification of transient coherent structures when applied to aeolian systems (e.g., Baas 2006; Ellis 2006). To identify statistically significant wind-blowing snow coupling, the wavelet coherence $(\mathrm{CH})$ and statistical significance testing method of Grinsted et al. (2004) is introduced for this blowing snow study. This is a complimentary technique to the wavelet maps of Ellis (2006), wavelet packet decomposition of Liu et al. (2012), and wavelet cospectra of Paterna et al. (2016).

Let $W^{x}(n, s)$ and $W^{y}(n, s)$ be the continuous wavelet transforms of the time series $\left\{x_{n}\right\}$ and $\left\{y_{n}\right\}$, respectively, where $n$ is time and $s$ is the scaling of the mother wavelet. Further define the cross wavelet transform of the two time series as $W^{x y}(n, s)=W^{x}(n, s) W^{y *}(n, s)$, where * indicates the complex conjugate of the wavelet transform. For the present research, the Morlet wavelet was chosen as the mother wavelet as it is well localized in both frequency and time and is useful for event extraction in geophysical time series (Grinsted et al. 2004; Ellis 2006). Following Liu (1994) and Torrence and Webster (1999), one can derive a measure $\mathrm{CH}_{n, s}(x, y)$ of the coherence in the cross-wavelet transform in the timefrequency domain:

$$
\mathrm{CH}_{n, s}^{2}(x, y)=\frac{\left|\left\langle s^{-1} W_{n}^{x y}(s)\right\rangle\right|^{2}}{\left\langle s^{-1} W_{n}^{x}(s)\right\rangle\left\langle s^{-1} W_{n}^{y}(s)\right\rangle},
$$

where \langle\rangle is a smoothing operator in time and scale, and multiplication by $s^{-1}$ converts values to energy density. The statistical significance testing of Grinsted et al. (2004) utilizing Monte Carlo simulations and background red noise was applied at the $5 \%$ significance level to all wavelet coherence results. The cone of influence (COI) demarcates the regions in the timefrequency domain where zero padding and edge effects from the wavelet transform improperly affect coherence calculations. To verify that significant coupling had been identified in each time series pair, $\mathrm{CH}$ maps for each recording were tested to determine if more than $5 \%$ of the scale-weighted area inside the COI contained statistically significant coherence. Time-averaged $\mathrm{CH}_{n, s}$, referred to as $\mathrm{MCH}_{s}$, also provided a measure of mean coherence in the frequency domain for each recording. Define

$$
\operatorname{MCH}_{s}(x, y)=\frac{1}{\mu\left(n_{s} \in \mathrm{COI}\right)} \int_{n_{s} \in \mathrm{COI}} \mathrm{CH}_{n, s}(x, y) d n,
$$

where $\mu\left(n_{s} \in \mathrm{COI}\right)$ is the measure of the length of the time series intersecting the COI at scale $s$. Further background on the theory of wavelets can be found in Daubechies (1992). Applications and comparisons of wavelet methods are outlined by Foufoula-Georgiou and Kumar (1994) and Torrence and Compo (1998) and in the signal processing text of Mallat (2008).

\section{2) Amplitude MOdULATION}

One limitation of using Fourier or wavelet coherence tests to characterize the coupling of turbulent bursts with blowing snow is that neither method clearly captures the influence of large-scale motions on highfrequency turbulence or snow transport energy across scales. The role of large-scale motions is increasingly important as strong topographically enhanced turbulent motions in this mountain region have been identified (Helgason and Pomeroy 2012) but the power spectra likely overlap with local processes, often preventing a clear spectral separation of large- and small-scale motions (Sievers et al. 2015). Thus, the relationship of large eddies (duration greater than $30 \mathrm{~s}$ ) with high-frequency, near-surface turbulence and blowing snow was further investigated with the theory of amplitude modulation.

Consider, for example, representing high-frequency local turbulent motions as a carrier signal $c(t)=\sin (4 \pi t)$, and larger atmospheric motions with a higher mean wind speed as a modulating signal $m(t)=2+\sin (\pi t)$. The 

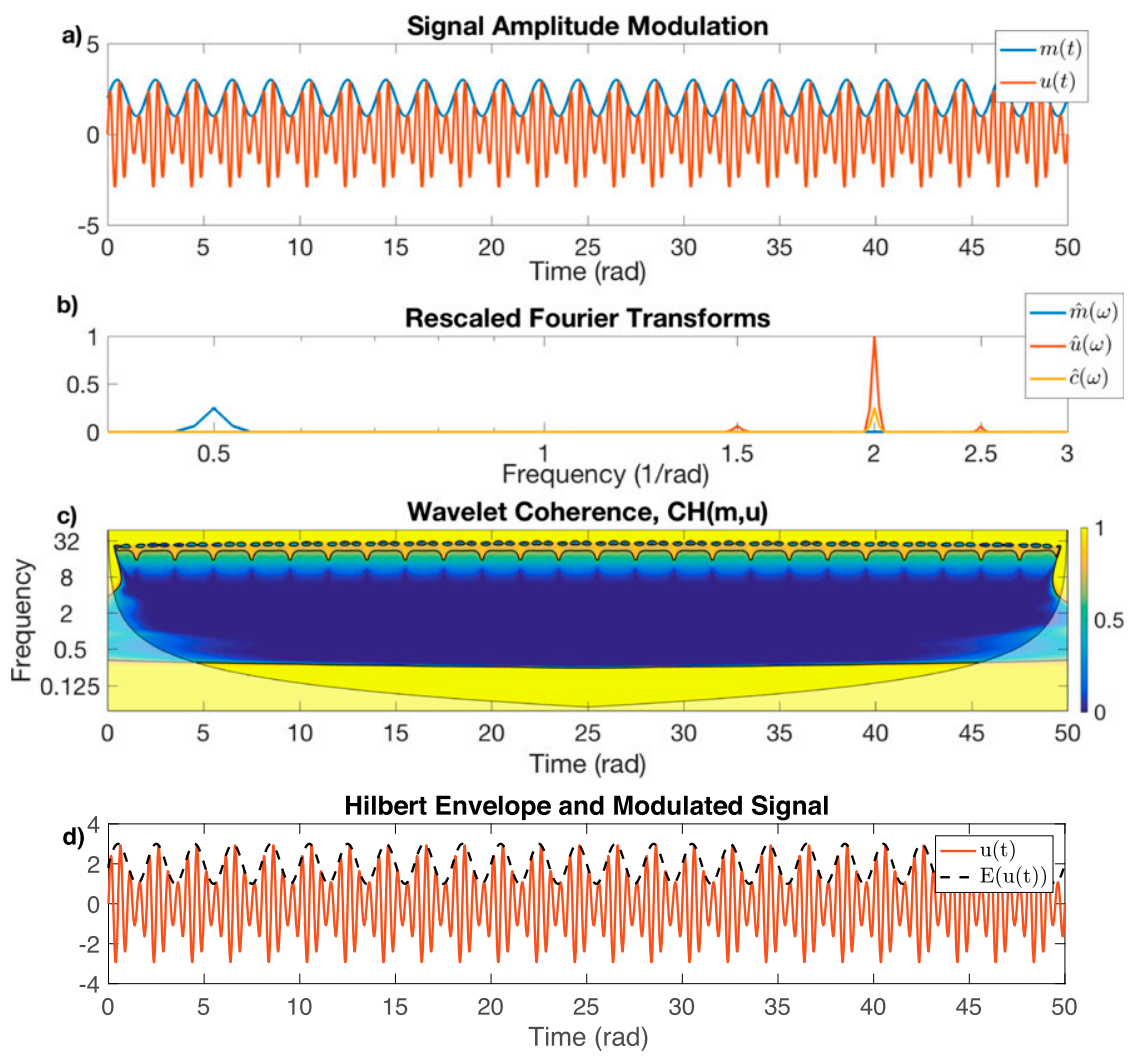

FIG. 2. (a) Synthetic example of amplitude modulation of high-frequency signal, (b) Fourier transforms of modulating and modulated signals showing mirroring of modulating energy, (c) wavelet coherence map of $\mathrm{CH}_{n, s}(m, u)$. Notably, there is no $0.5 \mathrm{rad}^{-1}$ coherence from the modulating signal $m(t)$ energy and (d) Hilbert transform recovered amplitude modulating signal.

resultant amplitude-modulated signal $u(t)=[2+m(t)] c(t)$ and $m(t)$ are displayed in Fig. 2a. With $\hat{m}(\omega)$ and $\hat{u}(\omega)$ being the Fourier transform of $m(t)$ and $u(t)$, respectively, $\hat{u}(\omega)$ in Fig. $2 \mathrm{~b}$ shows the mirroring of the energy content from $\hat{m}(\omega)$ around the base frequency of $c(t), 2 \pm$ $0.5 \mathrm{rad}^{-1}$. While the amplitude of the carrier signal has obviously been increased at the modulating signal's frequency, this influence is largely obscured in the Fourier transforms. Because of the broadband overlap of both low- and high-frequency motions in the atmosphere, extracting a signal responsible for modulating high-frequency turbulence with Fourier methods is realistically unfeasible. For clarity, the mirroring effect on the Fourier transforms is proven in more generality in the supplemental material.

Because of the translation of modulating signal energy away from its original frequency to each side of the carrier signal frequency, there is no evidence of coupling in the wavelet coherence map of $m(t)$ and $u(t)$ at the frequencies of either the carrier $\left(2 \mathrm{rad}^{-1}\right)$ or modulating signals $\left(0.5 \mathrm{rad}^{-1}\right)\left[\mathrm{CH}_{n, s}(m, u) \approx 0\right.$ in Fig. 2c]. With sufficient frequency separation in the power spectra of the carrier and modulating signals, however, the Hilbert transform can perfectly reconstruct the modulating signal. For a time series $x(t)$, define the Hilbert transform

$$
\mathcal{H}[x(t)]=\tilde{x}(t)=\frac{\mathrm{PV}}{\pi} \int_{-\infty}^{\infty} \frac{x(u)}{(t-u)} d u=x(t) *\left(\frac{1}{\pi t}\right),
$$

where PV is the Cauchy principal value, and $*$ denotes standard convolution. The Hilbert transform can also be regarded as the imaginary part of the analytic function $z(t)$ with $\operatorname{Re}(z)=x(t)$. Formally,

$$
z(t)=x(t)+i \tilde{x}(t)
$$

The modulus of $z(t)$ is called the envelope signal of $x(t)$, herein written $E[x(t)]$. Using the same modulating and carrier signals as in Fig. $2 \mathrm{a}, E[u(t)]$ is overlaid on $u(t)$ in Fig. $2 \mathrm{~d}$ and is identical to the modulating signal $m(t)$. This reconstruction of modulating signals is proven in more generality in the supplemental material. 
Mathis et al. (2009a) demonstrated a method to identify to what degree passing large-scale motions modulate high-frequency turbulence in sufficiently high Reynolds number flows. For a streamwise wind signal $u$, one first separates the signal into low- and high-frequency components, $u_{L}$ and $u_{H}$, respectively, at an appropriate cutoff frequency. The effect of amplitude modulation becomes evident after the same low-pass filter is applied to the Hilbert envelope of the high-frequency signal $E_{L}\left[u_{H}(t)\right]$. The degree to which the high-frequency turbulence was modulated can be identified when $E_{L}\left[u_{H}(t)\right]$ is compared with the low-frequency motions in $u_{L}$.

This method identifies nonlinear effects of large-scale motions on near-wall turbulence in the atmospheric surface layer that were missed in Fig. 2c. For the present study, it is proposed that the low-frequency component of streamwise wind speed $u_{L}$ represents large eddies (modulating signal) that amplify the magnitude of highfrequency surface fluctuations (carrier signal) $u_{H}$. A correlation coefficient can then be defined that measures the degree of amplitude modulation, that is, the influence of large-scale eddies on high-frequency turbulence:

$$
\mathrm{AM}_{u, u}=\frac{\overline{u_{L} E_{L}\left(u_{H}\right)}}{\sqrt{\overline{\overline{u_{L}^{2}}}} \sqrt{\overline{E_{L}\left(u_{H}\right)^{2}}}},
$$

where the overbar indicates temporal averaging. Note that because amplitude modulation inherently involves different scales of motions at different velocities, AM intentionally does not account for a difference in mean or variance in the two time series. Furthermore, all signals were standardized to have zero mean and unit variance prior to calculation of $\mathrm{AM}$ coefficients to account for different units and ranges of wind and snow signals. Background on amplitude modulation and the theory of Hilbert transforms can be found in Bendat and Piersol (2010).

\section{d. Turbulence characteristics}

Seventy-two turbulence statistics were calculated for each recording, including turbulence intensity, turbulence kinetic energy, friction velocity, drag coefficient (Stull 1988; Lykossov and Wamser 1995), dissipation length, energy flux, and several covariances. Reynolds stress time series were also decomposed following quadrant analysis with a hole size of one ( $\mathrm{Lu}$ and Willmarth 1973). The percent of Reynolds stress contributed by each quadrant of motion above this threshold was then calculated, as well as the temporal occurrence of each quadrant motion. As these values are compact simplifications of the flow conditions, correlations between them and wavelet coherence or the degree of amplitude modulation across the recordings may provide useful corollaries for semideterministic modeling with lower computational cost. Notable correlations are presented in the results.

\section{Results}

\section{a. Wavelet coherence}

Wavelet coherence was calculated for time series pairs of low-anemometer streamwise wind speed and blowing snow density $\mathrm{CH}_{n, s}\left(\rho_{\text {bs }}, u_{g}\right)$ as well as lowanemometer Reynolds stress and blowing snow density $\mathrm{CH}_{n, s}\left(\rho_{\mathrm{bs}}, \tau\right)$ for all 23 recordings. Examples of raw wind $\left(u_{g}\right.$ and $\left.\tau\right)$ and $\rho_{\mathrm{bs}}$ signals and their wavelet coherence maps $\mathrm{CH}_{n, s}$ from 3 March are shown in Fig. 3. Bold outlined regions of the coherence maps in Figs. $3 \mathrm{c}$ and $3 \mathrm{~d}$ indicate coherent events at the $5 \%$ significance level.

As was typical for all recordings, there is much greater coherence between blowing snow density and streamwise wind speed in Fig. $3 \mathrm{c}$ than that measured with Reynolds stress (Fig. 3d). In Fig. 3, statistically significant regions cover $48 \%$ and $4 \%$ of the COI for $\mathrm{CH}_{n, s}\left(\rho_{\mathrm{bs}}, u_{g}\right)$ and $\mathrm{CH}_{n, s}\left(\rho_{\mathrm{bs}}, \tau\right)$, respectively. The average area of significant wind structures coupled with snow was $19 \%$ for $u_{g}$ and $9 \%$ for $\tau$ over all recordings, with only 10 out of the 23 recordings showing significant coherence at the $5 \%$ level between $\tau$ and $\rho_{\text {bs }}$ for more than $5 \%$ of the area of the COI. Even the largest coherence measurements indicate highly intermittent structures of natural blowing snow at this site.

Time-averaged $\mathrm{CH}_{n, s}$ calculations $\left(\mathrm{MCH}_{s}\right)$ measured the mean coherence at each scale over an entire time series. The average $\mathrm{MCH}_{s}$ for the whole experiment is displayed in Fig. 4a with frequency ranges bin averaged for clarity. One standard deviation is shaded surrounding the mean of both Fig. 4 plots. The $\mathrm{MCH}_{s}$ provides similar information to magnitude-squared Fourier coherence with larger values indicating more coherence. Coherence monotonically increased with decreasing frequency between blowing snow and streamwise wind speed, whereas a possible coherence peak was found between Reynolds stress and blowing snow around $0.05 \mathrm{~Hz}$ in Figs. $4 \mathrm{a}$ and $4 \mathrm{~b}$. The measured coherence between the snow and either turbulence signal was equivalent above $0.35 \mathrm{~Hz}$. As $\mathrm{MCH}_{s}$ is a time average of $\mathrm{CH}_{n, s}$, the transient nature of intermittent blowing snow is not clearly captured.

In contrast, Fig. $4 \mathrm{~b}$ displays the mean percent of time (inside the COI) with $\mathrm{CH}_{n, s}\left(\rho_{\mathrm{bs}}, u_{g}\right)$ and $\mathrm{CH}_{n, s}\left(\rho_{\mathrm{bs}}, \tau\right)$ at $5 \%$ statistical significance for the same frequency bins over all recordings. This uses the temporal localization of wavelets to present how often transient but significant 

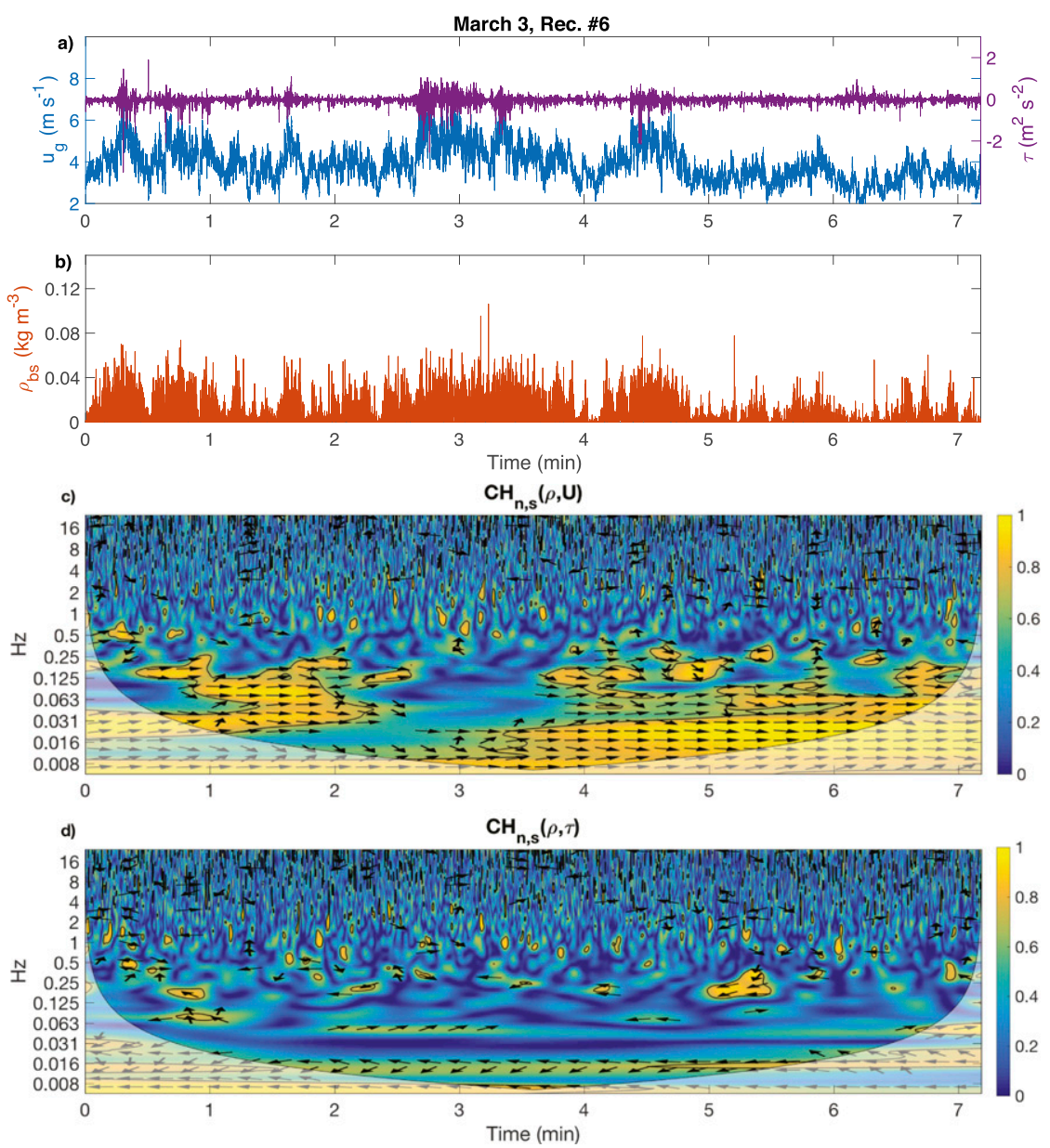

FIG. 3. (a) Streamwise wind speed and Reynolds stress for recording 6 on 3 Mar 2016. (b) Blowing snow density for the same recording. (c) Wavelet coherence for blowing snow and streamwise wind and (d) for blowing snow and Reynolds stress. In (c) and (d), bold lines surround 5\% significance events. Arrows indicate the phase relationship of the two signals, with in-phase pointing right and antiphase pointing left, and $90^{\circ}$ down being the wind leading the snow.

coherence occurred. Interestingly, Fig. $4 b$ shows there was always some statistically significant coupling in both pairs at all scales in the COI while low-frequency $(<0.35 \mathrm{~Hz})$ structures still dominated the bands of highest coherence. There was substantial low-frequency coherence below $f_{c}=0.06 \mathrm{~Hz}$ in $\mathrm{CH}\left(\rho, u_{g}\right)$ that was not present in $\mathrm{CH}(\rho, \tau)$, with significant coherence nearly 4 times more likely with streamwise wind speed. This is to be expected by the relatively low energy in $\tau$ at low frequencies (Hunt and Morrison 2000) that provides little energy to the cross-wavelet transforms [Eq. (1)]. Again, there was general agreement in coherence of blowing snow with either wind signal above $0.35 \mathrm{~Hz}$.

The edge effects associated with the Morlet wavelet prevent resolving coherence of blowing snow with atmospheric motions larger than approximately half the length of a recording, as they are outside the COI (Torrence and Compo 1998). This is a typical issue with time-frequency decompositions and is a manifestation of using finite-length time series and a nonzero minimum area of Heisenberg boxes (Weyl 1950). An analogous problem exists when resolving magnitudesquared coherence with Fourier methods where large fast Fourier transform windows allow lower-frequency coherence measurements but introduce more signal noise (Biltoft and Pardyjak 2009).

\section{b. Amplitude modulation}

Wavelet coherence (Figs. 3, 4) indicated that blowing snow responded most strongly to wind energy at long time scales (low frequencies) between $3 \mathrm{~s}$ and the limits of the COI. However, there was also coupling of $\rho_{\mathrm{bs}}$ to 

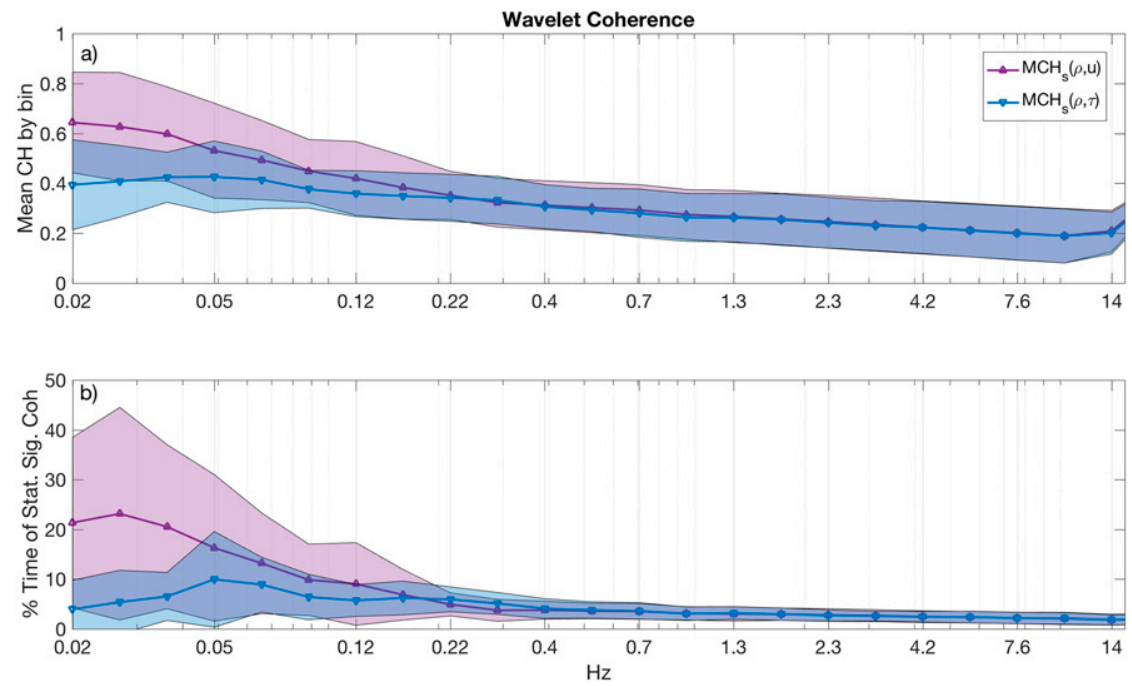

FIG. 4. (a) Frequency-binned $\mathrm{MCH}_{s}\left(\rho_{\mathrm{bs}}, \tau\right)$ and $\operatorname{MCH}_{s}\left(\rho_{\mathrm{bs}}, u_{g}\right)$ over all recordings and (b) the percent of temporal occurrence of $\mathrm{CH}\left(\rho_{\mathrm{bs}}, u_{g}\right)$ and $\mathrm{CH}\left(\rho_{\mathrm{bs}}, \tau\right)$ values that were statistically significant at $5 \%$ for the same bins. One standard deviation is shaded for all plots. Notice the higher coherence at lower frequencies for $\mathrm{CH}\left(\rho_{\mathrm{bs}}, u_{g}\right)$ and general agreement of coherence for $f>0.35 \mathrm{~Hz}$.

high-frequency $u$ and $\tau$ fluctuations of unknown origin over shorter time scales (Figs. 4a,b). The analyses of Baas (2003), Baas and Sherman (2005), and Ellis (2006) indicate that the brief coherent structures responsible for intermittent sand transport in their studies did not likely originate from surface instabilities. Thus, for all recordings, it was investigated whether the significant high-frequency coupling in section 3 a could be also be related to large-scale structures. More precisely, was there evidence of amplitude modulation in highfrequency turbulence, blowing snow, and coherence signals during the passage of top-down penetrating structures?

The ability to quantify amplitude modulation with Hilbert transforms [Eqs. (3) and (5)] is sensitive to the cutoff frequency separating large-scale and surface motions (Mathis et al. 2009a). The choice of scale separation in the current study is complicated by the topographical influence on turbulence spectra at the study site by the surrounding peaks (Mahrt and Gamage 1987; Sievers et al. 2015). As well, both wind measurements were obtained relatively close to each other and near the snow surface, preventing identification of a distinct outer region peak as found by Hutchins and Marusic (2007a). However, a transition from self-similar behavior to an inertial subrange $-5 / 3$ slope was seen near the frequency $f=0.06 \mathrm{~Hz}$ in the averaged power spectra for each night (Fig. 5). There was also a transition to higher turbulence energy at the lower measurement height for frequencies above this threshold (Fig. 5). Using the mean wind speed at $2 \mathrm{~m}$ as a proxy for convective velocity, this frequency corresponded to eddy length scales between 39 and $67 \mathrm{~m}$ during the recordings. Average integral time scales for the streamwise wind series were also found to be of this order of magnitude at $33 s=0.03 \mathrm{~Hz}^{-1}$. This is similar to a previous atmospheric boundary layer amplitude-modulation study that found the boundary layer depth $(\delta=60 \mathrm{~m}$ for their experiment) to be a suitable separating length scale (Mathis et al. 2009a). As there was no definitive measurement of the boundary layer depth at this mountain site, the cutoff frequency $f_{c}=0.06 \mathrm{~Hz}$ was chosen as a threshold to separate large-scale and small-scale motions. Varying the choice of threshold in the range from $f_{c}=0.12$ to $0.03 \mathrm{~Hz}$ did not affect the described analysis and results, though it did result in small variations in the degree of modulation AM [Eq. (5)].

The large motions defined by the low-pass filter in both the near-surface $u_{g, L}$ and upper anemometer $u_{h, L}$ streamwise wind signals were found to strongly modulate highfrequency near-surface turbulence $u_{g, H}$. The coefficients $\mathrm{AM}_{u_{h}, u_{g}}$ and $\mathrm{AM}_{u_{g}, u_{g}}$, as defined by Eq. (5), were found to be typically greater than or equal to those found in previous modulation studies (Mathis et al. 2009a) and are detailed in Table 2 . The consistently large AM values for either pair of turbulent wind signals $(\mathrm{AM} \in[0.4-0.8])$ are convincing evidence of the influence of low-frequency, large-scale events on high-frequency turbulence and suggest that many near-surface turbulence bursts were not a purely local phenomenon. Amplitude modulation of $\rho_{\mathrm{bs}}$ 

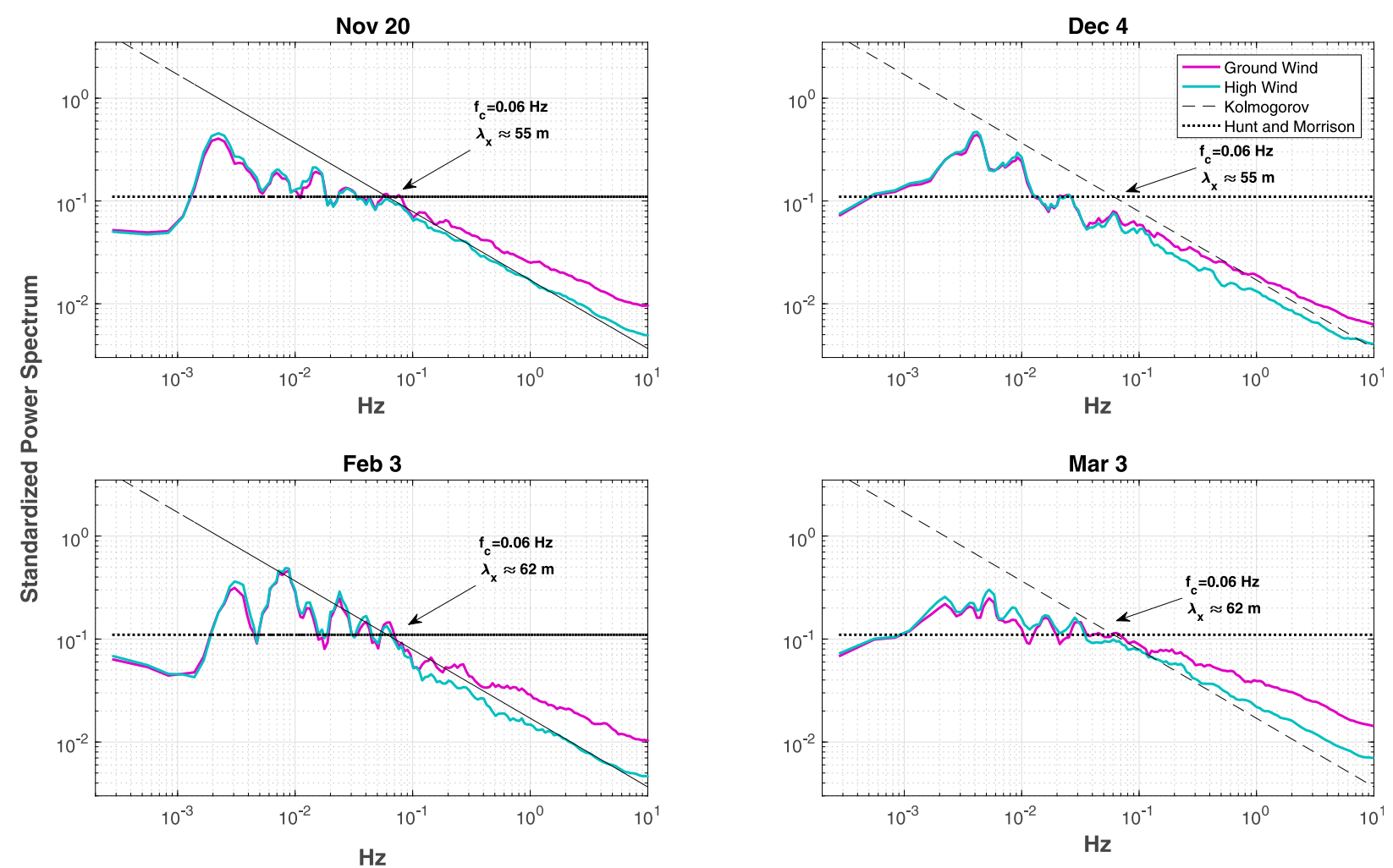

FIG. 5. Standardized premultiplied power spectral density of streamwise wind speed for $5 \mathrm{~h}$ at two measurement heights over four nights of recording. Self-similar (Hunt and Morrison 2000) and -5/3 slope (Kolmogorov 1941) lines overlaid to show transition and cutoff frequency $f_{c}=0.06 \mathrm{~Hz}$. Also note elevated high-frequency energy in ground wind signals above $f_{c}$. Date of 7 Feb omitted for plot clarity.

by upper-anemometer, large-scale motions was also quantified and can be found in Table 2 .

While the majority of recordings exhibited strong modulation (Table 2), there were several exceptions that are explained with quadrant analysis ( $\mathrm{Lu}$ and Willmarth 1973) in section 4. These values are italicized in Table 2. Also of note, in contrast to the results of Hutchins and Marusic (2007a), there was inconsistent amplitude modulation of Reynolds stress signals, and not all recordings showed clear modulation between low-frequency streamwise wind speed and high-frequency Reynolds stress.

Figure 6 displays an example of a time series of lowfrequency, upper-anemometer wind speed and highfrequency envelopes for the same recording as in Fig. $3\left(\mathrm{AM}_{u_{h}, u_{g}}=0.69, \mathrm{AM}_{u_{h}, \rho}=0.95\right)$. The raw wind and snow signals under analysis are shown in Fig. 6a. Figure $6 \mathrm{~b}$ shows the low-pass-filtered upper-anemometer wind signal $u_{h, L}$; the envelope of high-frequency blowing snow $E_{L}\left(\rho_{\mathrm{bs}, H}\right)$; and the envelope of highfrequency, near-surface turbulence $E_{L}\left(u_{g, H}\right)$, as well as purple dots during moments of extreme sweep Reynolds stress $\left\{t\left|u^{\prime}(t)>0, w^{\prime}(t)<0,\right| u^{\prime}(t) w^{\prime}(t) \mid>\operatorname{rms}\left(u^{\prime} w^{\prime}\right)\right\}$ from quadrant analysis (Lu and Willmarth 1973). For presentation clarity, all time series in Fig. $6 \mathrm{~b}$ have been standardized to have zero mean and unit variance.

Many local maxima in $E_{L}\left(\rho_{\mathrm{bs}, H}\right)$ and $E_{L}\left(u_{g, H}\right)$ are in phase with the passage of energetic low-frequency events at the upper anemometer (e.g., 0-1 min, 2.55 min in Fig. 6b). In general, the same atmospheric motions that modulated near-surface turbulence were often responsible for enhancing high-frequency components of blowing snow. Disregarding three outlier recordings on 20 November, 3 March, and 4 December described in section 4, there was strong linear correlation between $E_{L}\left(u_{g, H}\right)$ and $E_{L}\left(\rho_{\mathrm{bs}, H}\right)$, resulting in an average correlation coefficient over all nights of 0.54 .

The transient high-frequency coherence between wind and snow signals mentioned in section 3 a also appears to be connected to the passage of large-scale motions. To illustrate this, each time step of $\mathrm{CH}_{n, s}\left(\rho_{\mathrm{bs}}, u_{g}\right)$ was scale averaged over the Fourier frequencies greater than $0.35 \mathrm{~Hz}$ to obtain a mean coherency time series between only high-frequency components of snow and turbulence signals. This coherency time series was then low-pass filtered below the cutoff frequency $f_{c}=0.06 \mathrm{~Hz}$ to show the in-phase and out-of-phase relationship with large-scale motions. This time series is displayed as a dashed green 


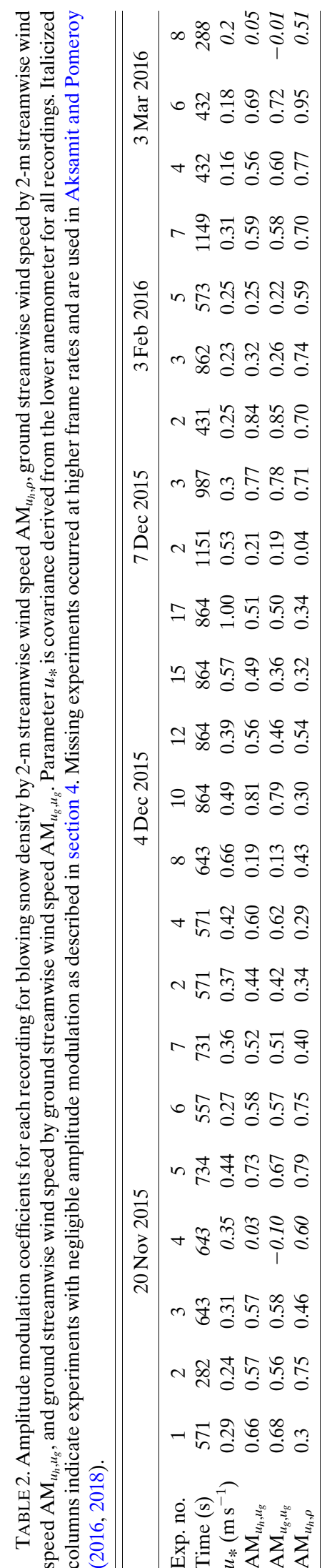

line $\left[\mathrm{CH}_{s>0.35}(\rho, u)_{L}\right]$ in Fig. $6 \mathrm{c}$ and is indicative of what was found in all recordings: many of the passing large motions that modulate high-frequency turbulence also coincide with stronger high-frequency coherence between wind and snow. This is also reflected in consistently high correlation coefficients between $\mathrm{CH}_{s>0.35}(\rho, U)_{L}$ and $E_{L}\left(u_{g, H}\right)$, with an average $r=0.57$ over all recordings, as discussed more in section 3c. Thus, it was the passage of large-scale wind structures that was responsible for both high- and low-frequency coherence between blowing snow transport and wind signals.

It is worth noting that, like the results of Baas (2006) and Liu et al. (2012), the snow transport signal maintained higher wavelet power spectral density than streamwise wind fluctuations at the upper end of the frequency spectrum, typically $>1 \mathrm{~Hz}$, showing a possible inertial effect of snow particles and the presence of a near-surface rebound energy separate from that gained from the wind.

\section{c. Connections with turbulence statistics}

Statistical associations were examined between measurements of average coherence and amplitude modulation and turbulence descriptors for each recording to discern if certain atmospheric conditions were more conducive to wind-snow coupling or amplitude modulation. Very few statistically significant correlations were found; for instance, no correlation was found with friction velocity, turbulence intensity, turbulence kinetic energy, or mean wind speed at either height. The strongest correlation discovered was between average high-frequency $(>0.35 \mathrm{~Hz})$ coherence and mean sonic temperature during the recordings $\left(r=0.8, P<\times 10^{-5}\right)$. That is, the warmer the temperature during the recording, the more high-frequency coherence between streamwise wind speed and blowing snow density that occurred. This may be a manifestation of entrainment of sensible heat into near-surface blowing snow. This association can also be explained by examination of the surface snow crystal habits coinciding with each temperature range. The dates of 20 November and $3 \mathrm{Feb}-$ ruary were the two coldest nights with the most significantly wind-scoured snow surfaces and the lowest high-frequency coherence. The date of 4 December was slightly warmer and also showed evidence of antecedent wind scouring. However, on this evening there were more pockets of loose snow that could easily be available for transport and a slight increase in high-frequency coherence. The dates of 7 December and 3 March were the two warmest nights with fresh loose snow available on the surface for transport. Thus, it appears that for intermittent transport, the increased drag forces present on larger, unbroken grains and increased availability of 

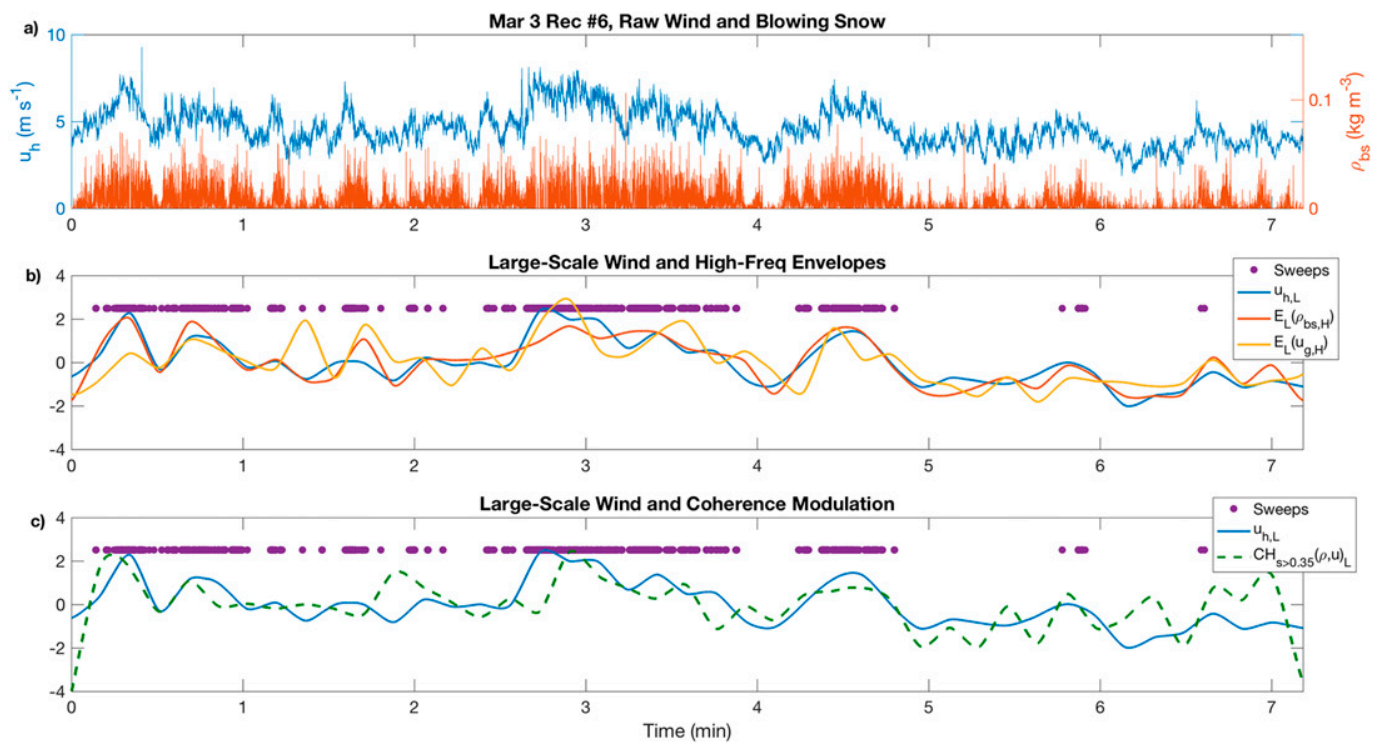

FIG. 6. Amplitude modulation of high-frequency wind and blowing snow signals by large-scale events. (a) Raw wind and blowing snow signals. (b) Notice correlation between low-pass wind signal $u_{h, L}$ and Hilbert transform envelopes of high-pass wind and snow signals $\left[E\left(\rho_{\mathrm{bs}, H}\right)\right.$ and $\left.E_{L}\left(u_{g, H}\right)\right]$. (c) Low-pass signal of high-frequency coherence $\mathrm{CH}_{s>0.35}\left(\rho_{\mathrm{bs}}, u_{g}\right)_{L}$ indicates many of the same low-frequency structures are generating periods of highfrequency coherence. Sweep structures are marked by purple dots and coincide with the strongest excursions in $u_{L}$ in (b) and (c).

fresh snow for transport on the warm nights were more relevant for high-frequency blowing snow response than the presence of low-inertia small grain sizes. This transport initiation dependence on snow grain type is consistent with the findings of Guyomarc'h and Mérindol (1998).

Further characterizing the relevant coherent turbulent structures is helpful for understanding the mechanisms in wind and snow transport modulation. For example, sweeps in Fig. 6b always coincide with local maxima of modulation envelopes or high-frequency coherence. This is further reflected by a fairly good correlation coefficient over the 23 recordings $(r \approx 0.6, P<0.005)$ between the percent of Reynolds stress generated by sweeps at the lower anemometer and the recording values of $\mathrm{AM}_{u_{g}, u_{h}}$, $\mathrm{AM}_{u_{g}, u_{g}}$, and $E_{u_{g}, \rho}$. This connection is physically justified by the definition of sweeps as downward accelerating motions that could penetrate and modulate surface turbulence. The correlation was not as strong with upper anemometer sweeps $(r \approx 0.2-0.4, P<0.06-0.25)$, which suggests that surface eddy blocking may have prevented penetration all the way to the snow for some motions. Correlations with quadrant two and quadrant one motions were not as prominent, but all three amplitude modulation coefficients were negatively correlated with the Reynolds stress contribution from inward motions $\left\{u^{\prime}(t)<0, w^{\prime}(t)<0\right\}$. There was no discernible relationship between average wavelet coherence in either frequency band and the presence of Reynolds stress from any quadrant motions. This is evidence of the difficulties encountered when describing turbulent two-phase flow with average statistical trends.

A weak positive correlation existed between mean blowing snow density and low-frequency coherence $(r=0.43, P<0.06)$, indicating rates of transport increased with increasing low-frequency $(f<0.35 \mathrm{~Hz})$ influence. A slightly more meaningful correlation $(r=0.7, P<0.0005)$ was found between the temporal percent of a recording with measured blowing snow and low-frequency coherence. This indicated a shift to increased low-frequency coherence when blowing snow was occurring and particles responding to a wider spectrum of low-frequency fluctuations above threshold wind speeds.

As the snowpack deepened over the season and the lower anemometer became closer to the snow surface, the amount of unmeasured high-frequency turbulence energy increased. This is especially true of 3 March, where low anemometer measurements occurred approximately $0.10 \mathrm{~m}$ above the snow surface and potentially $30 \%$ of high-frequency energy may have not been measured (van Boxel et al. 2004). It is suspected that the inclusion of additional high-frequency energy (e.g., with a hot-wire anemometer) would only enhance the already large highfrequency coherence values between turbulence and blowing snow transport $\mathrm{CH}_{s>0.35}\left(\rho_{\mathrm{bs}}, u_{g}\right)$ obtained on 
TABLE 3. Streamwise amplitude modulation $\mathrm{AM}_{u_{g}, u_{g}}$ in SLF blowing snow wind tunnel experiment (Paterna et al. 2016) for a variety of cutoff frequencies $f_{c}$ over nine experiments. This indicates the absence of high-frequency turbulence amplitude for a wide variety of scale separations in a typical blowing snow wind tunnel experiment.

\begin{tabular}{|c|c|c|c|c|c|c|c|c|c|c|}
\hline \multirow[b]{2}{*}{$u_{*}\left(\mathrm{~m} \mathrm{~s}^{-1}\right)$} & \multirow[b]{2}{*}{$f_{c}(\mathrm{~Hz})$} & \multirow{2}{*}{$\frac{\text { Exp 1 }}{0.23}$} & \multirow{2}{*}{$\frac{\operatorname{Exp} 2}{0.23}$} & \multirow{2}{*}{$\frac{\operatorname{Exp} 3}{0.22}$} & \multirow{2}{*}{$\frac{\operatorname{Exp} 4}{0.21}$} & \multirow{2}{*}{$\frac{\text { Exp 5 }}{0.26}$} & \multirow{2}{*}{$\frac{\operatorname{Exp} 6}{0.23}$} & \multirow{2}{*}{$\frac{\operatorname{Exp} 7}{0.25}$} & \multirow{2}{*}{$\frac{\operatorname{Exp} 8}{0.20}$} & \multirow{2}{*}{$\frac{\operatorname{Exp} 9}{0.25}$} \\
\hline & & & & & & & & & & \\
\hline & 6.37 & -0.01 & -0.03 & -0.04 & 0.00 & 0.02 & 0.04 & 0.03 & 0.06 & 0.03 \\
\hline & 3.18 & -0.07 & -0.07 & -0.11 & 0.01 & -0.03 & 0.00 & -0.04 & 0.01 & 0.01 \\
\hline & 1.59 & -0.16 & -0.15 & -0.15 & -0.08 & -0.06 & -0.05 & 0.02 & -0.04 & -0.02 \\
\hline & 0.80 & -0.17 & -0.12 & -0.10 & -0.12 & -0.09 & -0.05 & -0.03 & -0.04 & 0.02 \\
\hline & 0.40 & -0.11 & -0.26 & -0.28 & -0.12 & -0.10 & -0.06 & 0.04 & -0.09 & -0.03 \\
\hline & 0.20 & 0.08 & -0.25 & -0.29 & -0.16 & -0.13 & -0.09 & -0.14 & 0.03 & 0.13 \\
\hline & 0.10 & 0.09 & -0.08 & -0.33 & 0.13 & -0.09 & -0.12 & 0.06 & -0.42 & 0.15 \\
\hline & 0.05 & 0.08 & 0.03 & -0.60 & 0.04 & -0.08 & -0.21 & 0.00 & -0.85 & -0.04 \\
\hline & 0.02 & -0.25 & -0.01 & -0.84 & -0.16 & -0.02 & -0.60 & 0.74 & -0.94 & 0.55 \\
\hline
\end{tabular}

that night. As discussed above, the large coherence is most likely the result of increased drag with the fresh snow surface conditions, and not the absence of highfrequency wind measurements. Potential high-frequency losses for the two anemometers for each night of measurements are provided in the supplemental material.

\section{d. Wind tunnel comparison}

As the degree of amplitude modulation in turbulent boundary layers increases with increasing Reynolds number (Mathis et al. 2009a), understanding the contrasts between atmospheric flows at high Reynolds numbers and analogous wind tunnel experiments at low Reynolds numbers is vital for understanding how and whether to extend laboratory-derived wind-snow transport relationships to natural terrain (e.g., Paterna et al. 2016). To highlight the significant role amplitude modulation played in both high- and low-frequency wind-snow coupling at FMSL, an analogous amplitude modulation analysis of wind tunnel observations of streamwise wind fluctuations and streamwise blowing snow transport (Paterna et al. 2016) was performed. The degree of amplitude modulation was measured in nine $20-\mathrm{Hz}$ time series of $u^{\prime}$ during blowing snow events, as well as modulation of directional blowing snow flux by wind, at a variety of cutoff frequencies $\left(f_{c}=0.02-\right.$ $6.37 \mathrm{~Hz}$ ). As the Swiss Institute for Snow and Avalanche Research (SLF) wind tunnel where these data were collected has a $1 \mathrm{~m} \times 1 \mathrm{~m}$ cross section and an approximately 0.25 -m-deep logarithmic layer (Clifton et al. 2006), these separation scales encompass and exceed the largest eddies present in the boundary layer. Table 3 shows the results of the streamwise wind modulation analysis and is representative of the finding that amplitude modulation was not present in either signal $\left(\mathrm{AM}_{u_{g}, \rho}\right.$ and $\mathrm{AM}_{u_{g}, u_{g}} \ll 1$, often negative). Thus, in the wind tunnel, the turbulent structures of which the wind was composed appear rather distinct from those found in the alpine outdoors for a subset of the friction velocities observed at FMSL.

\section{Discussion}

The coupling of wind and near-surface snow saltation in the atmospheric surface layer proves to be complex, with nonlinear momentum transfer over many time and length scales. Near-surface, high-frequency turbulence was strongly modulated by passing large-scale, lowfrequency motions measured $160 \mathrm{~cm}$ above. These same large eddies were responsible for modulating the highfrequency components of the blowing snow density signal as seen by the strong correlation between the high-frequency envelopes generated by the streamwise wind and blowing snow signals. In the presence of the large-scale motions, wavelet coherence between wind and snow signals was strongest in the low-frequency range, with significant high-frequency coherence being largely intermittent. However, high-frequency coherence peaks also coincided with passage of the same low-frequency motions. The question remains whether this coupling is the result of snow transport fluctuations responding to modulated high-frequency turbulence over short time scales, or if by the passage of large-scale events, the stochastic dynamics of surface impacts and rebound are amplified, resulting in a synchronous increase in high-frequency snow transport energy. As also noted by Jacob and Anderson (2017), amplitude modulation in nature may indeed play a crucial role in generating turbulent fluctuations sufficient to initiate blowing snow transport.

Two recordings with negligible turbulence modulation occurred on 20 November and 3 March (italicized in Table 2). These recordings coincide with more positive Reynolds stress $\tau$ being generated by $u^{\prime}<0$ and $w^{\prime}>0$ 
(ejection) events than $u^{\prime}>0$ and $w^{\prime}<0$ (sweep) events. Ejections outweigh sweeps for only one other recording, experiment 8 on 4 December, during which $\mathrm{AM}_{u_{g}, u_{h}}$ and $\mathrm{AM}_{u_{g}, u_{g}}$ were also less than average ( 0.19 and 0.13 , respectively). Table 2 shows relatively low modulation coefficients for experiment 2 on 7 December $\left(\mathrm{AM}_{u_{g}, u_{h}}=0.21, \mathrm{AM}_{u_{g}, u_{g}}=0.19\right.$, and $\left.\mathrm{AM}_{u_{g}, \rho}=0.04\right)$, a recording that coincides with diminished presence of both sweeps and ejections and a relatively low total Reynolds stress. During these four recordings, the reduced presence of sweep events corresponds well with a decrease in large-scale motions penetrating to the surface and thus limited amplitude modulation. Somewhat counterintuitively, the spurious 20 November, 3 March, and 4 December recordings all maintained good snowwind modulation coefficients $\mathrm{AM}_{u_{g}, \rho}$, adding another layer of complexity to the mechanics of near-surface momentum balance. Regardless, these data support the role of sweeps as large-scale structures that modulate surface turbulence and snow transport.

In general, wavelet coherence and amplitude modulation analyses suggest a stronger dependence of snow transport on instantaneous wind speed than Reynolds stress, in agreement with recent aeolian sand studies (Sterk et al. 1998; Schönfeldt and von Löwis 2003; Leenders et al. 2005). While the statistical testing of wavelet coherence does not determine a causal relationship, there is only a $5 \%$ probability that coherence peaks occur solely by chance. When limiting analysis to small-scale motions at frequencies greater than $0.35 \mathrm{~Hz}$, mean wavelet coherence $\left(\mathrm{MCH}_{s}\right)$ of blowing snow density and Reynolds stress was as strong as that with streamwise wind speed. This may indicate why Reynolds stress and friction velocity often scale with snow transport behavior in wind tunnels where large eddies are not present. However, Paterna et al. (2016) also documented high-frequency coupling between snow transport and streamwise wind speed for low-strength, steady-state saltation. Here, in contrast to Paterna et al. (2016), there was no notable increase in low-frequency blowing snow energy caused by sediment transport decoupling from the wind as low-frequency energy and coherence dominated all FMSL recordings (Fig. 4). Closer examination of any decoupling as described by Paterna et al. (2016) is not possible with this dataset given the large temporal variability in transport in this gusty mountain environment. However, a connection exists between nights with a decrease in high-frequency coherence and the fragmentation of grains and reduction in particle drag. This fragmentation may prove to be an additional mechanism resulting in the decoupling noted during high-strength saltation by Paterna et al. (2016).
As modulation of near-surface turbulence by largescale influences can also be manifested in fluctuations of Reynolds stress (Mathis et al. 2013), the amplitude modulation found indicates that common turbulence statistics, such as friction velocity $u_{*}$, used to model blowing snow transport are being strongly modified by large-scale motions. Interestingly, there was less evidence of amplitude modulation between low- and highfrequency bands of Reynolds stress than that found by Hutchins and Marusic (2007a). This may be caused by external environmental factors such as different surface roughness, momentum loss to snow transport, or considerably more complicated terrain and is subject for further investigation.

The analysis of turbulence mechanics in a wind tunnel blowing snow study showed negligible amplitude modulation when compared to the alpine observations, indicating an absence of the same magnitude of nonlinear momentum transfer that is found in nature. Thus, adapting wind tunnel-derived scaling relationships (e.g., Nishimura and Hunt 2000; Clifton et al. 2006; Horender et al. 2013) to complex terrain is largely dependent on how topographically influenced motions, and their influence on surface turbulence statistics, can be represented as modifications of simpler cases. This has implications beyond the impact of wind fluctuations on models of steady-state blowing fluxes (e.g., Sørensen 1997). For example, evidence of amplitude modulation has been found in the roughness sublayer (Anderson 2016), the region represented by roughness lengths $z_{0}$ in log-law models. The common practice of modifying $z_{0}$ to accommodate a wind momentum deficit during blowing snow (Pomeroy and Gray 1990; Liston and Sturm 1998; Lehning et al. 2000) may also need to be reevaluated in this context.

Aksamit and Pomeroy (2018) showed that sweeps are responsible for considerable blowing snow initiation and surface transport, especially during intermittent transport conditions. Through the positive correlation of amplitude modulation coefficients and sweep-generated Reynolds stress, the penetration of these large-scale structures also appears responsible for much of the nearsurface turbulence modulation. Separating Reynolds stress into components of large-scale modulation and purely local instability, as by Mathis et al. (2013), is the next step in reconciling scaling relationships derived in wind tunnels and the turbulent structures found in the atmospheric surface layer (ASL). The strong degree of amplitude modulation likely indicates that many of the largest near-surface turbulence events resulted from the passage of large-scale motions and not local surface instabilities.

Further investigation with a wider span of measurement heights may permit implementation of turbulence 
modulation in driving a blowing snow initiation or transport model. Such an approach would be beneficial to delimit for the necessary resolution of large-eddy simulations. The eddies with length scales of $30-60 \mathrm{~m}$ that modulated the amplitude of near-surface motions at FMSL are at the frontier of alpine blowing snow LES models (Vionnet et al. 2017). Further investigations may help realize statistically representative lower-boundary conditions (Anderson 2016) as well as improve windsnow interactions in the saltation layer in LES.

\section{Conclusions}

This research examined how the structure of turbulence in the atmospheric surface layer affects nearsurface blowing snow fluxes at a mountain site. The effects are multiscale and involve complex interactions between high- and low-frequency motions. Intermittent blowing snow transport responded to large low-frequency streamwise motions that modulated the amplitude of high-frequency turbulence. Because of this amplitude modulation, large-scale motions do not act simply as a shift in mean wind speed on local instabilities, but modify the dynamics of the surface momentum balance by increasing the amplitude of high-frequency turbulence. This modulation effect is important to characterizing turbulence for particle transport calculations, as the coherence between wind speed and snow transport signals also increases under footprint of these structures.

Large-scale sweep motions influenced near-surface turbulence and blowing snow fluxes across all measured frequencies. In light of the evidence of nonlinear momentum transfer across a wide spectrum of scales, determining the appropriate assumptions about the relative magnitude of structures and time scales for blowing snow transport is necessary for transport modeling. Future research to better understand near-surface turbulence amplitude modulation may permit reconciliation of the need for high-frequency, near-surface streamwise velocity measurements in blowing snow models and the more standard and widely available low-frequency micrometeorological observations through near-surface turbulence modulation models. A clearer understanding of how specific turbulent structures affect near-surface turbulence will better characterize the differences between wind tunnel and alpine blowing snow and provide insight for adapting steady-state, low Reynolds number scaling relationships to gusty natural conditions.

Continued observations of amplitude modulation over rough natural surfaces can help suggest improvements to surface interaction models for atmospheric large-eddy simulations (Anderson 2016) and to highresolution large-eddy simulations of snow transport (e.g., Groot Zwaaftink et al. 2014). Because the amplitude modulation in both the turbulence and blowing snow signals found in this outdoor setting is not present in wind tunnels, considerable advancement in the field of sediment transport in complex terrain will likely only come after appropriately addressing the nonlinear dynamics influencing near-surface turbulent motions and further investigating two-phase flow turbulence in outdoor boundary layers.

Acknowledgments. The authors acknowledge funding from the Canada Foundation for Innovation, the Natural Sciences and Engineering Research Council of Canada, the Changing Cold Regions Network, Canada Research Chairs, the Global Institute for Water Security and Alberta Agriculture and Forestry. The assistance of the Fortress Mountain Resort in logistics is gratefully noted. Data are available at http://dx.doi.org/10.20383/ 101.010 .

\section{REFERENCES}

Aksamit, N. O., and J. W. Pomeroy, 2016: Near-surface snow particle dynamics from particle tracking velocimetry and turbulence measurements during alpine blowing snow storms. Cryosphere, 10, 3043-3062, https://doi.org/10.5194/ tc-10-3043-2016.

- , and - 2018: The effect of coherent structures in the atmospheric surface layer on blowing-snow transport. Bound.Layer Meteor., https://doi.org/10.1007/s10546-017-0318-2, in press.

Anderson, W., 2016: Amplitude modulation of streamwise velocity fluctuations in the roughness sublayer: Evidence from largeeddy simulations. J. Fluid Mech., 789, 567-588, https://doi.org/ 10.1017/jfm.2015.744.

Baas, A. C. W., 2003: The formation and behavior of aeolian streamers. Ph.D. dissertation, University of Southern California, $412 \mathrm{pp}$.

_ 2006: Wavelet power spectra of aeolian sand transport by boundary layer turbulence. Geophys. Res. Lett., 33, L05403, https://doi.org/10.1029/2005GL025547.

- 2008: Challenges in aeolian geomorphology: Investigating aeolian streamers. Geomorphology, 93, 3-16, https://doi.org/ 10.1016/j.geomorph.2006.12.015.

— and D. J. Sherman, 2005: Formation and behavior of aeolian streamers. J. Geophys. Res., 110, F03011, https://doi.org/ 10.1029/2004JF000270.

Bauer, B., J. Yi, S. Namikas, and D. Sherman, 1998: Event detection and conditional averaging in unsteady aeolian systems. J. Arid Environ., 39, 345-375, https://doi.org/10.1006/ jare.1998.0380.

_ I. J. Walker, A. C. W. Baas, D. W. T. Jackson, C. M. Neuman, G. A. Hesp, and F. S. W. Patrick, 2013: Critical reflections on the coherent flow structures paradigm in aeolian geomorphology. Coherent Flow Structures at Earth's Surface, J. G. Venditti et al., Eds., Wiley-Blackwell, 111-134, https://doi.org/ 10.1002/9781118527221.ch8.

Bendat, J. S., and A. G. Piersol, 2010: Random Data: Analysis and Measurement Procedures. 4th ed. John Wiley, 566 pp. 
Biltoft, C. A., and E. R. Pardyjak, 2009: Spectral coherence and the statistical significance of turbulent flux computations. J. Atmos. Oceanic Technol., 26, 403-410, https://doi.org/ 10.1175/2008JTECHA1141.1.

Bintanja, R., 1998: The interaction between drifting snow and atmospheric turbulence. Ann. Glaciol., 26, 167-173, https:// doi.org/10.1017/S0260305500014750.

- 2000: Snowdrift suspension and atmospheric turbulence. Part I: Theoretical background and model description. Bound.-Layer Meteor., 95, 343-368, https://doi.org/10.1023/A:1002676804487.

Bisantino, T., F. Gentile, P. Milella, and G. T. Liuzzi, 2010: Effect of time scale on the performance of different sediment transport formulas in a semiarid region. J. Hydraul. Eng., 136, 56-61, https://doi.org/10.1061/(ASCE)HY.1943-7900.0000125.

Chapman, C., I. J. Walker, P. A. Hesp, B. O. Bauer, R. G. D. Davidson-Arnott, and J. Ollerhead, 2013: Reynolds stress and sand transport over a foredune. Earth Surf. Processes Landforms, 38, 1735-1747, https://doi.org/10.1002/esp.3428.

Clifton, A., J. D. Rüedi, and M. Lehning, 2006: Snow saltation threshold measurements in a drifting-snow wind tunnel. J. Glaciol., 52, 585596, https://doi.org/10.3189/172756506781828430.

Daubechies, I., 1992: Ten Lectures on Wavelets. Society for Industrial and Applied Mathematics, $357 \mathrm{pp}$.

Dyunin, A. K., and V. Kotlyakov, 1980: Redistribution of snow in the mountains under the effect of heavy snow-storms. Cold Reg. Sci. Technol., 3, 287-294, https://doi.org/10.1016/0165-232X(80)90035-X.

Ellis, J. T., 2006: Coherent structures and aeolian saltation. Ph.D. dissertation, Texas A\&M University, 123 pp.

Foufoula-Georgiou, E., and P. Kumar, 1994: Wavelets in Geophysics. Academic Press, 373 pp.

Freitag, D. R., and T. McFadden, 1997: Introduction to Cold Regions Engineering. American Society of Civil Engineers, 738 pp.

Gordon, M., S. Savelyev, and P. A. Taylor, 2009: Measurements of blowing snow, part II: Mass and number density profiles and saltation height at Franklin Bay, NWT, Canada. Cold Reg. Sci. Technol., 55, 75-85, https://doi.org/10.1016/j.coldregions.2008.07.001.

Grinsted, A., J. C. Moore, and S. Jevrejeva, 2004: Application of the cross wavelet transform and wavelet coherence to geophysical time series. Nonlinear Processes Geophys., 11 561-566, https://doi.org/10.5194/npg-11-561-2004.

Groot Zwaaftink, C. D., M. Diebold, S. Horender, J. Overney, G. Lieberherr, M. B. Parlange, and M. Lehning, 2014: Modelling small-scale drifting snow with a Lagrangian stochastic model based on large-eddy simulations. Bound.-Layer Meteor., 153, 117-139, https://doi.org/10.1007/s10546-014-9934-2.

Guyomarc'h, G., and L. Mérindol, 1998: Validation of a forecasting application of blowing snow periods. Ann. Glaciol., 26, 138143, https://doi.org/10.1017/S0260305500014701.

Helgason, W., and J. W. Pomeroy, 2012: Characteristics of the near-surface boundary layer within a mountain valley during winter. J. Appl. Meteor. Climatol., 51, 583-597, https://doi.org/ 10.1175/JAMC-D-11-058.1.

Horender, S., C. D. Groot Zwaaftink, B. Walter, and M. Lehning, 2013: Intermittent drifting snow-Combining experimental and model studies. Proc. Int. Snow Science Workshop, Grenoble-Chamonix Mont-Blanc, France, International Snow Science Workshop, 104-107, http://arc.lib.montana.edu/ snow-science/objects/ISSW13_paper_O2-06.pdf.

Hunt, J. C. R., and J. F. Morrison, 2000: Eddy structure in turbulent boundary layers. Eur. J. Mech., 19B, 673-694, https://doi.org/ 10.1016/S0997-7546(00)00129-1.
Hutchins, N., and I. Marusic, 2007a: Large-scale influences in near-wall turbulence. Philos. Trans. Roy. Soc. London, A365, 647-664, https://doi.org/10.1098/rsta.2006.1942.

$\longrightarrow$, and — 2007b: Evidence of very long meandering features in the logarithmic region of turbulent boundary layers. J. Fluid Mech., 579, 1-28, https://doi.org/10.1017/S0022112006003946.

Jacob, C., and W. Anderson, 2017: Conditionally averaged largescale motions in the neutral atmospheric boundary layer: Insights for aeolian processes. Bound.-Layer Meteor., 162, 21-41, https://doi.org/10.1007/s10546-016-0183-4.

Kaimal, J. C., and J. J. Finnigan, 1994: Atmospheric Boundary Layer Flows: Their Structure and Measurement. Oxford University Press, 289 pp.

Kok, J. F., E. J. R. Parteli, T. I. Michaels, and D. B. Karam, 2012: The physics of wind-blown sand and dust. Rep. Prog. Phys., 75, 10 901, https://doi.org/10.1088/0034-4885/75/10/106901.

Kolmogorov, A., 1941: The local structure of turbulence in incompressible viscous fluid for very large Reynolds numbers. Dokl. Akad. Nauk SSSR, 30, 301-305.

Leenders, J. K., J. H. van Boxel, and G. Sterk, 2005: Wind forces and related saltation transport. Geomorphology, 71, 357-372, https://doi.org/10.1016/j.geomorph.2005.04.008.

Lehning, M., J. Doorschot, and P. Bartelt, 2000: A snowdrift index based on SNOWPACK model calculations. Ann. Glaciol., 31, 382-386, https://doi.org/10.3189/172756400781819770.

Lenaerts, J. T. M., M. R. van den Broeke, J. H. van Angelen, E. van Meijgaard, and S. J. Déry, 2012: Drifting snow climate of the Greenland ice sheet: A study with a regional climate model. Cryosphere, 6, 891-899, https://doi.org/10.5194/tc-6-891-2012.

Li, L., and J. W. Pomeroy, 1997: Estimates of threshold wind speeds for snow transport using meteorological data. J. Appl. Meteor., 36, 205-213, https://doi.org/10.1175/1520-0450 (1997)036<0205:EOTWSF $>2.0 . C O ; 2$.

Liston, G., and M. Sturm, 1998: A snow-transport model for complex terrain. J. Glaciol., 44, 498-516, https://doi.org/ 10.1017/S0022143000002021.

Liu, J., Y. Wang, and Y. Zhang, 2009: Stationary wavelet-based analysis and simulation of unsteady wind in aeolian sand transport. Proc. Ninth Int. Conf. on Electronic Measurement and Instruments, Beijing, China, IEEE, 3789-3794, https://doi. org/10.1109/ICEMI.2009.5274176.

,-- , and B. Yang, 2012: Wavelet packet analysis of particle response to turbulent fluctuation. Adv. Powder Technol., 23, 305-314, https://doi.org/10.1016/j.apt.2011.04.002.

Liu, P. C., 1994: Wavelet spectrum analysis and ocean wind waves. Wavelets in Geophysics, E. Foufoula-Georgiou and P. Kumar, Eds., Academic Press, 151-166.

Lu, S. S., and W. W. Willmarth, 1973: Measurements of the structure of Reynolds stress in a turbulent boundary layer. J. Fluid Mech., 60, 481-511, https://doi.org/10.1017/S0022112073000315.

Lykossov, V. N., and C. Wamser, 1995: Turbulence intermittency in the atmospheric surface layer over snow-covered sites. Bound.Layer Meteor., 72, 393-409, https://doi.org/10.1007/BF00709001.

Mahrt, L., and N. Gamage, 1987: Observations of turbulence in stratified flow. J. Atmos. Sci., 44, 1106-1121, https://doi.org/ 10.1175/1520-0469(1987)044<1106:OOTISF>2.0.CO;2.

Mallat, S., 2008: A Wavelet Tour of Signal Processing: The Sparse Way. Elsevier, 805 pp.

Mathis, R., N. Hutchins, and I. Marusic, 2009a: Large-scale amplitude modulation of the small-scale structures in turbulent boundary layers. J. Fluid Mech., 628, 311-337, https://doi.org/ 10.1017/S0022112009006946. 
J. P. Monty, N. Hutchins, and I. Marusic, 2009b: Comparison of large-scale amplitude modulation in turbulent boundary layers, pipes, and channel flows. Phys. Fluids, 21, 11703, https://doi.org/10.1063/1.3267726.

- N. Hutchins, and I. Marusic, 2011: A predictive inner-outer model for streamwise turbulence statistics in wall-bounded flows. J. Fluid Mech., 681, 537-566, https://doi.org/10.1017/ jfm.2011.216.

— I. Marusic, S. I. Chernyshenko, and N. Hutchins, 2013: Estimating wall-shear-stress fluctuations given an outer region input. J. Fluid Mech., 715, 163-180, https://doi.org/10.1017/ jfm.2012.508.

Nemoto, M., and K. Nishimura, 2004: Numerical simulation of snow saltation and suspension in a turbulent boundary layer. J. Geophys. Res., 109, D18206, https://doi.org/10.1029/ 2004JD004657.

- _ _ - S. Kobayashi, and K. Izumi, 2004: Numerical study of the time development of drifting snow and its relation to the spatial development. Ann. Glaciol., 38, 343-350, https:// doi.org/10.3189/172756404781815202.

Nishimura, K., and J. C. R. Hunt, 2000: Saltation and incipient suspension above a flat particle bed below a turbulent boundary layer. J. Fluid Mech., 417, 77-102, https://doi.org/ 10.1017/S0022112000001014.

Otsu, N., 1979: A threshold selection method from gray-level histograms. IEEE Trans. Syst. Man Cybern., 9, 62-66, https:// doi.org/10.1109/TSMC.1979.4310076.

Paterna, E., P. Crivelli, and M. Lehning, 2016: Decoupling of mass flux and turbulent wind fluctuations in drifting snow. Geophys. Res. Lett., 43, 4441-4447, https://doi.org/10.1002/ 2016GL068171.

—_ — , and ——, 2017: Wind tunnel observations of weak and strong snow saltation dynamics. J. Geophys. Res. Earth Surf., 122, 1589-1604, https://doi.org/10.1002/ 2016JF004111.

Pomeroy, J. W., and D. Gray, 1990: Saltation of snow. Water Resour. Res., 26, 1583-1594, https://doi.org/10.1029/ WR026i007p01583.

- D. M. Gray, and P. G. Landine, 1993: The Prairie Blowing Snow Model: Characteristics, validation, operation. J. Hydrol., 144, 165-192, https://doi.org/10.1016/0022-1694 (93)90171-5.

Scarchilli, C., M. Frezzotti, P. Grigioni, L. De Silvestri, L. Agnoletto, and S. Dolci, 2010: Extraordinary blowing snow transport events in East Antarctica. Climate Dyn., 34, 11951206, https://doi.org/10.1007/s00382-009-0601-0.
Schönfeldt, H.-J., and S. von Löwis, 2003: Turbulence-driven saltation in the atmospheric surface layer. Meteor. Z., 12, 257-268, https://doi.org/10.1127/0941-2948/2003/0012-0257.

Schweizer, J., B. Jamieson, and M. Schneebeli, 2003: Snow avalanche formation. Rev. Geophys., 41, 1016, https:/doi.org/ 10.1029/2002RG000123.

Sievers, J., T. Papakyriakou, S. Larsen, M. M. Jammet, S. Rysgaard, M. K. Sejr, and L. L. Sørensen, 2015: Estimating local atmospheresurface fluxes using eddy covariance and numerical Ogive optimization. Atmos. Chem. Phys., 15, 2081-2103, https://doi.org/ 10.5194/acp-15-2081-2015.

Sørensen, M., 1997: On the effect of time variability of the wind on rates of aeolian sand transport. Aarhus Geoscience, Vol. 7, Aarhus University, 73-77.

Sterk, G., F. G. Jacobs, and J. H. Van Boxel, 1998: The effect of turbulent flow structures on saltation sand transport in the atmospheric boundary layer. Earth Surf. Processes Landforms, $\mathbf{2 3}$ 877-887, https://doi.org/10.1002/(SICI)1096-9837(199810)23: $10<877:: A I D-E S P 905>3.0 . C O ; 2-R$.

Stull, R., 1988: An Introduction to Boundary Layer Meteorology. Kluwer Academic, 666 pp.

Torrence, C., and G. P. Compo, 1998: A practical guide to wavelet analysis. Bull. Amer. Meteor. Soc., 79, 61-78, https://doi.org/ 10.1175/1520-0477(1998)079<0061:APGTWA > 2.0.CO;2.

— monsoon system. J. Climate, 12, 2679-2690, https://doi.org/ 10.1175/1520-0442(1999)012<2679:ICITEM >2.0.CO;2.

van Boxel, J., G. Sterk, and S. Arens, 2004: Sonic anemometers in aeolian sediment transport research. Geomorphology, 59, 131-147, https://doi.org/10.1016/j.geomorph.2003.09.011.

Venditti, J. G., and S. J. Bennett, 2000: Spectral analysis of turbulent flow and suspended sediment transport over fixed dunes. J. Geophys. Res., 105, 22 035-22 047, https://doi.org/ 10.1029/2000JC900094.

Vionnet, V., E. Martin, V. Masson, C. Lac, F. N. Bouvet, and G. Guyomarc'h, 2017: High-resolution large eddy simulation of snow accumulation in alpine terrain. J. Geophys. Res. Atmos., 122, 11 005-11 021, https://doi.org/10.1002/2017JD026947.

Weyl, H., 1950: The Theory of Groups and Quantum Mechanics. Dover, 448 pp.

Wiggs, G. F. S., and C. M. Weaver, 2012: Turbulent flow structures and aeolian sediment transport over a barchan sand dune. Geophys. Res. Lett., 39, L05404, https://doi.org/10.1029/2012GL050847.

Xuan, J., 2004: Turbulence factors for threshold velocity and emission rate of atmospheric mineral dust. Atmos. Environ., 38, 1777-1783, https://doi.org/10.1016/j.atmosenv.2003.12.030. 